\title{
WestVirginiaUniversity
}

THE RESEARCH REPOSITORY @ WVU

Graduate Theses, Dissertations, and Problem Reports

2020

\section{Effect of sire breed on grass-based lamb production}

Camren L. Maierle

clm0070@mix.wvu.edu

Follow this and additional works at: https://researchrepository.wvu.edu/etd

Part of the Sheep and Goat Science Commons

\section{Recommended Citation}

Maierle, Camren L., "Effect of sire breed on grass-based lamb production" (2020). Graduate Theses,

Dissertations, and Problem Reports. 7527.

https://researchrepository.wvu.edu/etd/7527

This Thesis is protected by copyright and/or related rights. It has been brought to you by the The Research Repository @ WVU with permission from the rights-holder(s). You are free to use this Thesis in any way that is permitted by the copyright and related rights legislation that applies to your use. For other uses you must obtain permission from the rights-holder(s) directly, unless additional rights are indicated by a Creative Commons license in the record and/ or on the work itself. This Thesis has been accepted for inclusion in WVU Graduate Theses, Dissertations, and Problem Reports collection by an authorized administrator of The Research Repository @ WVU. For more information, please contact researchrepository@mail.wvu.edu. 
Effect of sire breed on grass-based lamb production

Camren Layne Maierle

Thesis submitted to the Davis College of Agriculture, Natural Resources and Design at West Virginia University in partial fulfillment to the requirement for the degree of

Master of Science in Animal Physiology

\author{
Scott A. Bowdridge, Ph.D. \\ Scott P. Greiner, Ph.D. \\ Domingo Mata-Padrino, Ph.D. \\ Division of Animal and Nutritional Sciences \\ Morgantown, West Virginia \\ 2020
}

Keywords: breed, parasites, performance, sheep, terminal sire,

Texel

Copyright 2020 Camren L. Maierle 


\section{Abstract \\ Effect of sire breed on grass-based lamb production}

\section{Camren L. Maierle}

Improvement of lamb performance in low-input operations may prove vital for the sustainability of eastern US sheep production. Maintaining growth while improving carcass conformation using terminal sire crossbreeding systems may increase value in a pasture-based system. Therefore, the aim of this study was to compare effects of terminal sire breed on parasitism, growth, marketability of grazing lambs. Suffolk $(\mathrm{SU} ; \mathrm{n}=2)$ and Texel $(\mathrm{TX} ; \mathrm{n}=2)$ sires were mated to commercial ewes at the WVU Organic Farm. April-born lambs were managed on pasture as one group until weaning (mid-June), then were separated into 3 replicates per sire breed. Lambs were rotationally grazed for 93-d with paddock movement every 10-d and supplemented at a rate of $2 \%(16 \% \mathrm{CP})$ bodyweight. Weights were collected at weaning and then weekly for the duration of the study. Fecal egg counts (FEC) and FAMACHA scores were collected bi-weekly. Ultrasound measures of ribeye area (REA) were obtained at study conclusion and lambs were marketed at a graded auction. Sire breed did not impact weaning weight or growth rate. However, TX-sired lambs required fewer deworming treatments than SUsired lambs (39\% vs. $12 \% ; P<0.01)$. FAMACHA scores were numerically lower in TX vs. SUsired lambs (1.58 vs. $1.96 ; P<0.01$. Texel-sired lambs had greater REA (11.57 vs $9.42 \mathrm{~cm}^{2} ; P<$ 0.01 ) and graded better at auction. Texel-sired lambs sold for $\$ 27 / \mathrm{cwt}$. more than Suffolk-sired lambs. These data demonstrate that the desirable composition of TX-sired lambs translated into greater market value. 


\section{Acknowledgements}

Completion of this degree would not have been possible without the dedication of numerous individuals. The author would first like to thank the members of his committee; Drs. Scott Bowdridge, Scott Greiner and Domingo Matta-Padrino. Their guidance and assistance in the various aspects of this project were essential to its success. The leadership and guidance provided by committee chair, Dr. Bowdridge, is greatly appreciated and will always be remembered and cherished. On both a personal and professional level his to share knowledge and wisdom will always be remembered. The personal improvement and daily input offered, will change scientific and personal outlook for the remainder of the authors life.

An extensive thank you must go out to the Bowdridge lab for their assistance with sampling and logistics of the project. The project would not have been possible without the help of Roger Rohrbaugh, Reese Tuckwiller, and Andrew Weaver and their unwavering and always entertaining help with grazing rotations as well as forage sampling. A thank you owed to the staff at the WVU Organic farm and manager Teresa Koster for their management of the ewe flock prior to the start of the project and during the winter months.

A thank you is also necessary for the author's family, and the support provided during this time. Without the love and lifelong support shown over the past 25 years this degree would not be possible, and more importantly, enjoyable. The final thank you could not be forgotten for the author's wife, the amount of sacrifice and support provided has been second to none, and the foundation that always remained constant. 


\section{Contents}

Abstract t...1.

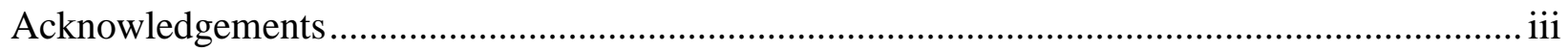

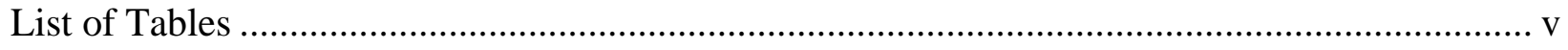

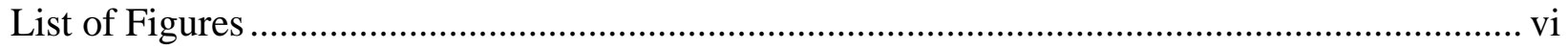

Chapter 1: Literature Review........................................................................................ 1

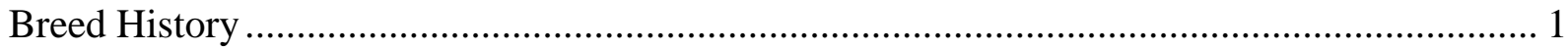

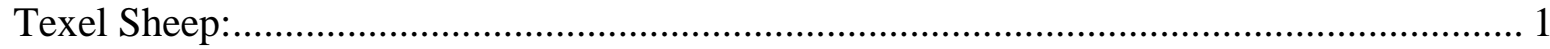

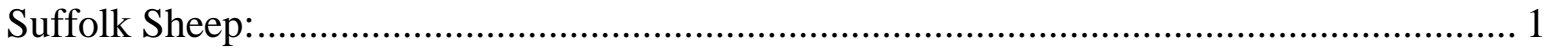

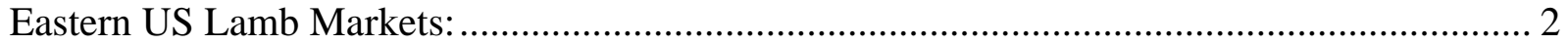

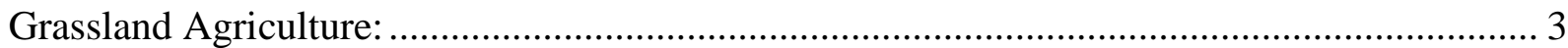

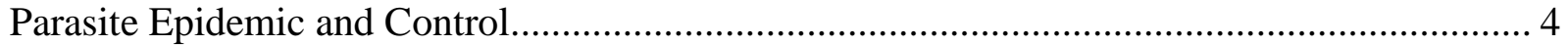

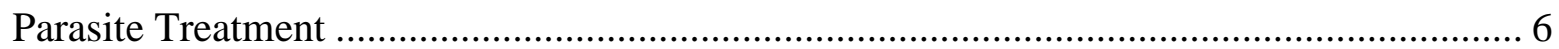

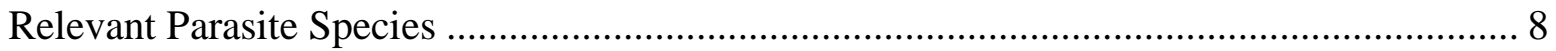

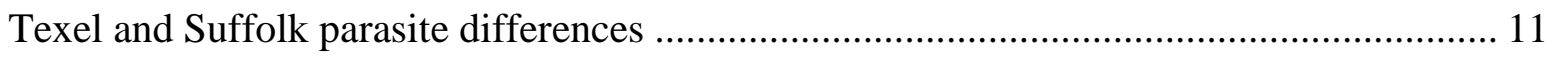

Terminal sire comparison of critical performance traits .................................................... 12

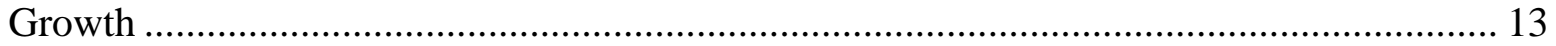

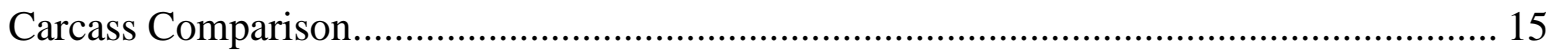

Chapter 2: Materials and Methods ...................................................................................... 17

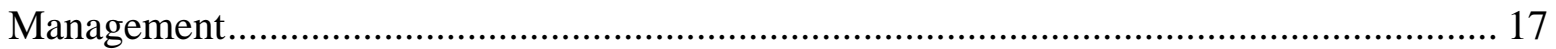

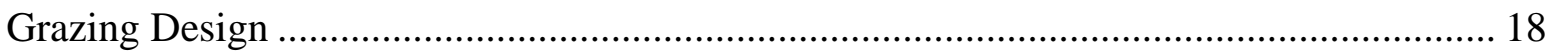

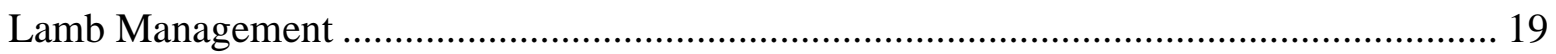

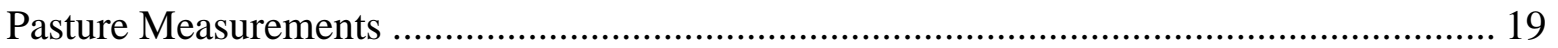

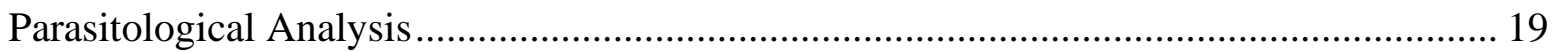

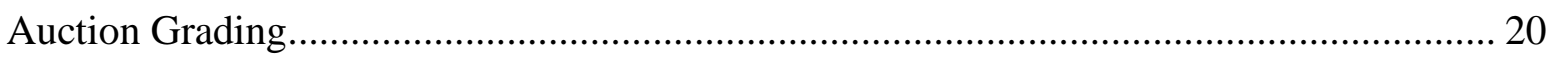

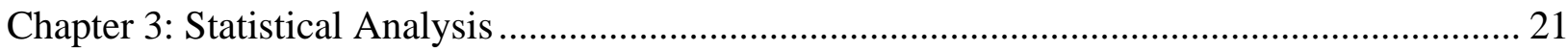

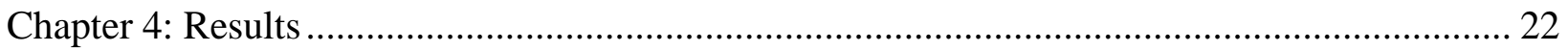

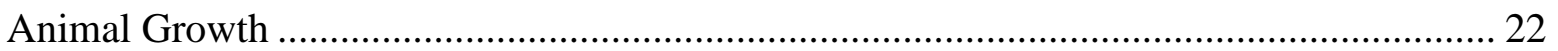

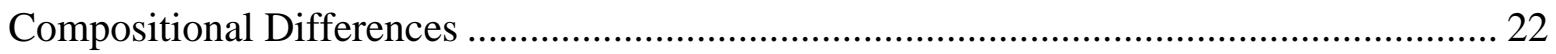

Auction Grading and Pricing ....................................................................................... 22

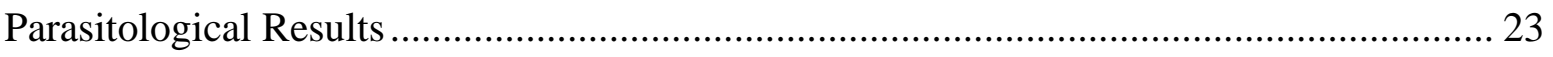

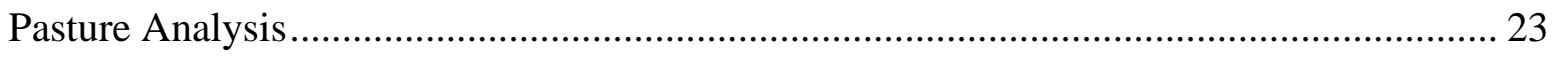

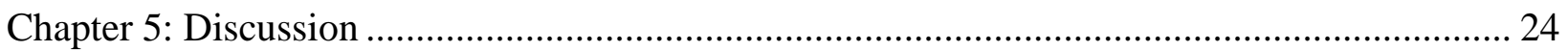

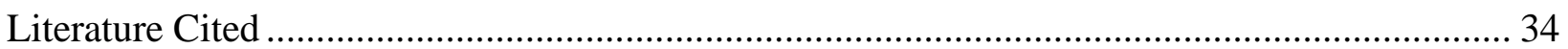




\section{List of Tables}

Table 1: Production parameters of Texel- and Suffolk-sired offspring $\ldots \ldots \ldots \ldots \ldots \ldots \ldots \ldots . \ldots 28$

Table 2: Auction grading of Texel- and Suffolk-sired offspring $\ldots \ldots \ldots \ldots \ldots \ldots \ldots \ldots \ldots \ldots \ldots$

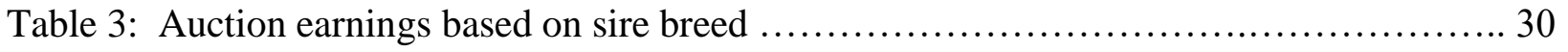




\section{List of Figures}

Figure 1: Growth measures of Texel- and Suffolk-sired offspring ...................... 31

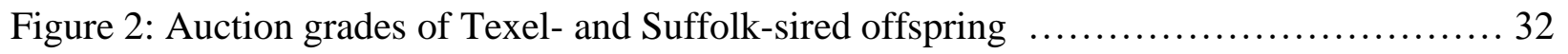

Figure 3: Parasite infection of Texel- and Suffolk-sired offspring $\ldots \ldots \ldots \ldots \ldots \ldots \ldots \ldots \ldots \ldots \ldots \ldots$ 


\section{Chapter 1: Literature Review}

\section{Breed History}

\section{Texel Sheep:}

The Texel (TX) breed originated in the Netherlands and was named after the Isle of Texel where they were established in the early nineteenth century. Texels, from Finland and Denmark, were imported to the United States in 1985 by researchers at the US Meat Animal Research Center in Clay Center, Nebraska. Initially, 20 bred TX ewes and 5 Danish TX rams were imported from separate flocks. Selection of imported stock emphasized genetic diversity as well as growth rate (Leymaster and Jenkins, 1993). In European countries, TX sheep have been the terminal sire of choice for decades. Previous European studies demonstrated that TX sheep excel in muscling and leanness compared to other terminal sire breeds (Cameron and Drury, 1985; More O'Ferrall and Timon, 1977). The rationale for importing TX was to explore potential use in US production aiming to improve carcass merit of commercial lambs.. In addition to carcass merit, others have found that Texels exhibited parasite resistance when compared to Suffolk (SUF) sheep (Good et al., 2005).

\section{Suffolk Sheep:}

Suffolk (SUF) sheep originated in England in the early nineteenth century from a cross between Southdown rams and Norfolk Horned ewes. Originally imported in 1919, this blackfaced breed rapidly gained popularity among commercial sheep operations as a terminal sire. Today, SUF sheep are the predominant terminal sire used in US sheep operations because of their complementarity with white-face wool breed ewes, superior growth and improved carcass traits. Utilization of SUF rams as terminal sires in all environments may not be appropriate as 
SUF sheep lack parasite resistance needed to survive in parasite burdened regions. Thus, lack of a parasite-resistant terminal sire continues to limit grass-based production systems in this region.

\section{Eastern US Lamb Markets:}

Traditional lamb markets make up the majority of total revenue generated by annual lamb sales in the United States. However, in the eastern US, a large part of lamb sales is derived from non-traditional or ethnic markets. These ethnic markets revolve around religious holidays and are predominantly associated with middle eastern culture. Lambs for non-traditional markets are generally direct-to-the-consumer sales and select auctions in the eastern United States. Lambs sourced for these markets tend to be slaughtered under 100lbs of liveweight and primarily target 40-80 lb. lambs, marketed shortly after weaning. Lambs being slaughtered in federally-inspected facilities have been in steady decline, however the ethnic markets have remained stable (Shiflett et al., 2010). It is estimated that only $20 \%$ of lambs slaughtered in federally-inspected facilities are sold into ethnic markets; accounting for approximately 500,000 lambs per year (Shiflett et al., 2010). In the eastern US, New Holland Sales Stables (New Holland, PA) is the largest lamb market selling an annual average of 117,462 sheep and lambs. Additionally, live auctions throughout Ohio, such as Mt. Hope Auction, are comparable in size and pricing for live sheep and lamb sales in the eastern US These sale locations have been popular for sourcing nontraditional lambs used by ethnic populations in east coast cities. Lambs sold in these eastern auctions are sorted on physical composition and sold on a live weight basis, thus, providing a premium to lambs that are more mature at a younger age. Despite a decline in the national sheep population, sales have remained strong at both New Holland and Mt. Hope auction yards. 


\section{Grassland Agriculture:}

Grassland agriculture is invaluable for the future of the US sheep industry. A consequence of grassland utilization is exposing animals to parasites, therefore, grazing practices should include strategies to control GIN. This segment of production specifically targets eastern and midwest regions of the US, largely due to terrain limitations of conventional cropping enterprises. Intensively managing these grassland regions has resulted in increased biodiversity along with improved soil and water quality (Bengston et al., 2019). Grazing practices of this region can support mature animal production during times of maintenance, growth, and lactation in properly managed scenarios. Lamb growth to slaughter was studied in Canada comparing grazing lambs (GL), ad libitum concentrate (CF), and limited concentrate (LC) fed lambs, who also had access to forage. Lambs on CF diets showed greater ADG and carcass weights at harvest than LC, or GL (Jacques et al., 2011). On average GL and LC lambs needed forty additional days on feed to reach an appropriate slaughter weight. All lambs showed similar muscling, however CF lambs had greater fat thickness at harvest. Lambs raised on forage alone can grow and produce a lean marketable carcass, though it may require supplementation to improve efficiency (Jacques et al., 2011).

Importance of intensive management strategies to limit parasite pressure during grazing seasons has been utilized in non-conventional operations for a number of years. Implementation of rotational, multi-species, or mob grazing have been shown to assist in the control of GIN, mitigating the need for anthelmintic treatment. Fewer lambs require deworming in rotationally grazed operations when compared to lambs maintained on continuously grazed forage (Burke et al., 2009). Previous work in Australia compared grazing strategies and their impact on parasite control. Intensive-rotational grazing (IRG) was carried out by moving paddocks every 5 days 
with 100 days of rest period for regrowth. Sheep grazed in the IRG group had 46\% lower FEC than other treatment groups (Colvin et al., 2008). Further testing also showed no difference in immune response to GIN, suggesting there was no sign of additional genetic parasite resistance between groups. Control of GIN species showed a specific reduction of Haemonchus contortus in IRG animals, explained by the ability of IRG management system to interrupt the $H$. contortus lifecycle (Colvin et al., 2008). Management of forage-based livestock agriculture is essential for the sustainability of US food supply. The ability to find alternative and improved methods in management of grassland ecosystems promotes the invaluable biodiversity found in them. One of the greatest concerns in these operations is how to minimize impacts of GIN infection on reduced growth and animal death.

\section{Parasite Epidemic and Control}

Parasite infection is of great concern for small ruminant producers in the US and worldwide. In $20158.6 \%$ of all non-predator death loss, was due to internal parasites (USDA, 2015). Other causes of death, higher than parasitic infection were lambing problems, old age, and unknown causes $(12.1 \%, 24.3 \%$, and $13.2 \%$ respectively). Extensive research examining internal parasitism in sheep reveals that $86 \%$ of these studies have reported a negative impact of GIN on sheep productivity (Mavrot et al., 2015). Included in the 88 studies were impacts of GIN on growth rate, wool production, as well as milk production. A negative correlation was found in $84 \%$ of these studies when looking at growth rate, when naïve and infected animals were tested. This negative correlation was also observed in $100 \%$ of milk production studies and $74 \%$ of wool production studies when examining both naïve and infected animals (Mavrot et al., 2015). The impact of GIN on productivity affects profitability on a multitude of levels. In Australia 
alone, the cost of parasitism is associated with millions of dollars of annual losses when decreased growth rate, and wool production are taken into account (Sackett et al., 2006).

Loss due to parasitism is no different in the US as the National Animal Health Monitoring System (NAHMS) published in 1996 that internal parasites were of a top health concern and GIN were of moderate to high burden in 62\% of operations in the US (USDAAPHIS-VS-NAHMS, 1996). Later reports indicated that in all operations, 7.9\% of producers lost lambs due to GIN in 2009, this number increased in 2014 to $9.2 \%$ of lamb losses as a result of GIN. Eastern US producers reported lamb loss due to GIN, was $14.2 \%$, and almost double what was reported in central and western regions of the US (7.9\%) (NAHMS, 2012).

Small ruminant health concerns due to GIN disproportionately affect the eastern US, where warm and humid conditions provide an excellent environment for parasites. Health concerns caused by GIN range from anemia to death loss in severe cases (Whittier et al., 2009). Historical practices to control GIN revolved around regular treatment of grazing animals with anthelmintics. These prophylactic treatments were carried out as often as every 21-28 days with broad spectrum anthelmintics, as directed by veterinarian and agricultural professionals (Terrill et al., 2012). This method of treatment was thought to consistently keep animals parasite free and productive; allowing for greater weight gain, and stable body condition of grazing livestock. This practice of parasite control was the basis for development and increasing prevalence of anthelmintic resistance in parasite populations (Kaplan,2004). In the late 1990's, cases of individual operations showing complete anthelmintic resistance to multiple dewormers, along with an evolving resistance to others, began to occur. Further examination demonstrated an increase of anthelmintic resistance on a greater proportion of farms in the southeastern US 
(Terrill et al., 2012). Development of anthelmintic resistance quickly revealed an emerging need for alternative strategies to sustain profitable sheep production.

\section{Parasite Treatment}

Anthelmintics are classified in three different categories consisting of benzimidazoles, nicotinic agonists, and macrolytic lactones. These three classes of anthelmintics are separated by their unique mode of parasite control. Within the last 30 years there has been only one new anthelmintic developed for use in small ruminants. Amino-acetonitrile derivatives (Monepantel) was a new class of dewormer released in 2009 but has yet to be approved for use in the US (Kaplan et al., 2012). Without new anthelmintics in sight, integrated parasite control (IPC) methods have been developed to mitigate the impact of parasitism.

Alternatives such as copper oxide wire particles (COWP) have also proven to be an effective tool. Studies carried out in southeastern US examined efficacy and dosing rates of COWP in both sheep and goats. Results indicated that COWP were effective in eliminating parasites that reside in the abomasum, such as $H$. contortus (Soli et al., 2010). Reduction in FEC, up to 97\%, was observed after COWP administration (Burke et al., 2004). Additionally, no side effect of copper toxicity was found using dosages less than $6 \mathrm{~g}$ (Burke et al., 2004). Thus, COWP can be effective in reducing FEC, thus lowering potential for reinfection.

A newer alternative, BioWorma ${ }^{\circledR}$, takes the IPC approach to controlling infective larvae in a pasture environment. This method utilizes a fungus that develops traps larvae in the environment during the free-living stages of $H$. contortous life cycle. Spores from Duddingtonia flagrans fungi are protected in the digestive system allowing for complete passage through the body and are deposited with feces in the pasture environment. This nematophagous fungus then develops a network of hyphae entrapping larvae. Trials in Australia have demonstrated parasite 
reduction of up to $86 \%$ in worm populations on pasture (Healey et al., 2018). Reduction of parasites on pasture decreases the chance for re-infection, resulting in a decrease in host FEC (Healey et al., 2018). This product has been approved for use in the US as well as Australia and may be a useful alternative for operations with low anthelmintic efficacy.

Additional parasite control measures utilize selective deworming through subjective evaluation of anemia levels, better known as the FAMACHA@ system. Small ruminants are evaluated with this on-farm test by scoring redness of the ocular mucous membrane. Depending on mucous membrane color, a score is given to asses severity of anemia (ranging 1-5). Animals that fall into categories 1 and 2 are healthy and do not require treatment. Animals at scores of 3 or higher are suggested to require deworming treatment (Burke et al., 2007). Selecting animals to be dewormed based on level of anemia allows for lower treatment cost as well as reducing rate of anthelmintic resistance development. Eliminating chemotherapeutic treatment of animals is ideal for operations striving to produce certified organic or "all-natural" products. If general health and nutrition are well managed in the flock, FAMACHA scoring may be used to identify animals that are consistently under heavy worm burden and used as a culling metric in effort to improve genetic resistance (Terrill, 2012).

Genetic selection for parasite resistance is the best option for long term sustainability in problematic parasite regions. Selection for parasite resistance could also be a long-term solution to regular anthelmintic treatment (Terrill, 2012). Selection of animals for increased genetic resistance has been made possible through the National Sheep Improvement Program (NSIP) which provides Estimated Breeding Values (EBV's) that quantify fecal egg count reduction. Utilizing genetic resistance for parasitism has improved the sustainability and popularity of the Katahdin breed. These alternatives provide opportunity for producers to expand operational sizes 
with limited burden of anthelmintic resistant GIN, allowing forage-based production to remain a viable option in the eastern US

\section{Relevant Parasite Species}

Nematode parasites of concern to the US sheep industry are categorized as Trichostrongylid. This family consists of Teladorsagia circumcincta, Trichostrongylus colubriformis and Haemonchus contortus. Teladorsagia circumcincta, also known as the brown stomach worm, is problematic for sheep and causes gastroenteritis (McNeilly et al. 2009). Residing in the abomasum, $T$. circumcincta matures in the abomasal gastric glands, disrupting conversion of pepsinogen to pepsin and ablating host ability to properly digest feedstuffs. Young lambs are at greatest risk, with symptoms including decreased weight gain and diarrhea (Zajac et al. 2006). T. colubriformis, or the Bankrupt Worm, resides in the small intestine and is symptomatic in stressed animals or during heavy worm burden. These symptoms result in economic losses due to weight loss along with diarrhea. T. colubriformis has created a larger concern in sheep focused countries such as Australia and New Zealand and has shown to be zoonotic parasite via fecal oral contamination (Zajac et al, 2006).

The GIN of primary concern in small ruminant production is the blood feeding parasite Haemonchus contortus. Belonging to the Trichostronglidea family, it is commonly referred to as the "barber-pole worm" (Mortensen et al., 2003). H. contortus adult females have a reproductive tract that intertwines with the digestive system creating a barber-pole appearance after the worms' have ingested blood from their host. Adult worms are equipped with a lancet that perforates the abomasal wall creating blood flow and ingestion by the worm. Adult worms ingest up to 200-600 $\mu 1$ of blood/day causing host anemia. If worm and larval burden are extremely high, blood feeding can cause rapid animal death which is known as acute haemonchosis 
(Springer, 2018). Unlike other GIN, H. contortus does not cause diarrhea in the host, limiting visual detection of infection at early stages (Zajac et al. 2006). H. contortus females can produce 10,000-15,000 eggs/day, increasing chances of re-infection, or spread of infection to other animals (Springer, 2018). Eggs are excreted in host feces and once in the environment eggs develop into larvae. During environmental stages, these larvae molt two additional times, developing into infective third-stage larvae (L3). Infective larvae migrate with evaporative moisture up and down grass and animals then ingest L3 while grazing. Ingested larvae travel with digesta until reaching the abomasum and their larvae develop into adults within 17-21 day timeframe and begin to produce eggs after copulation (Zajac et al. 2006). Egg output of heavily infected animals rapidly contaminates pastures, creating potential for additional animal infection. Another factor challenging control of this parasite is their ability to undergo hypobiosis, or a state of arrested development. Hypobiosis delays larval development within the host, during a time of year detrimental for larval development on pasture. Hypobiosis in the western hemisphere terminates in the spring, and larvae develop into adults generating greater egg output. Heavy egg output occurring after parturition allows for lambs to be infected during an optimal time for parasite development. The rapid direct lifecycle of $H$. contortus coupled with hypobiosis and the worms' blood-feeding nature are what makes this parasite such a large concern worldwide.

Parasite resistance in sheep is mediated by a variety of factors such as genetics, animal age, and prior parasite exposure. Resistance to certain species of parasites also varies greatly across and within breed. Selection for superior individuals can be a means by which producers can mitigate effects of parasitism and combat development of anthelmintic resistance. 
St. Croix (STC), Barbados Blackbelly, and Florida Native sheep have been identified as parasite resistant, as they were developed in tropical climates. Research conducted has compared these breeds to domestic breeds, in effort to discover immunological mechanisms regulating resistance. St. Croix sheep have been utilized extensively in this research and have shown greater immunity with primary H. contortus infections than other breeds. Gamble and Zajac (1992) compared STC to Dorset lambs (DL) examining artificially, and naturally infected resistance to H. contortus. This experiment demonstrated greater resistance of STC to H. contortus in secondary infections compared to DL, consistent with earlier studies. Naturally infected STC lambs had significantly lower egg output, as well as a $99 \%$ fewer abomasal $H$. contortus larvae shown in necropsy than DL. Further research has evaluated at immune response shortly following challenge infections of $H$. contortous. When compared to white-faced wool breeds, STC lambs had lower levels of larval establishment. Purebred STC lambs also had greater levels of circulating total white blood cell counts (9.76 vs. 7.49 cells $/ \mathrm{ml} \times 10^{6}$ in whole blood) (Bowdridge et al., 2015). These studies indicate an innate ability of STC to clear parasitic infection and prevent larval establishment without the use of anthelmintic (Gamble and Zajac, 1992).

St. Croix sheep, much like other parasite-resistant breeds, lack adequate production measures to justify use in traditional commercial sheep operations (Wildeus, 1997). Poor carcass quality and growth potential has been detrimental to their utilization and potential for inclusion into crossbreeding programs. However, with the creation of the Katahdin (KT) breed of sheep in the 1950's, this wool-less composite has grown in popularity for their parasite resistance stemming from STC lineage (Burke et al., 2003). Trials at the Dale Bumpers Small Farms Research Center in Arkansas compared performance of STC, KT and Dorper (DP) sired lambs 
for growth and carcass parameters. The DP was used as a terminal sire on STC ewes to produce lambs with improved carcass traits without sacrificing the ability to shed their hair coat. Lambs sired by DP rams had greater hot carcass weight than KT and STC lambs (29.9 kg vs. $24.1 \mathrm{~kg}$ and $21.6 \mathrm{~kg}$ respectively). However KT lambs and DP had a similar dressing percentage, both higher than STC lambs (53.7\% and 52.8\% vs. 49\% respectively) (Burke et al., 2003). With the influx of producers in the eastern US raising parasite resistant KT sheep, there is additional need for carcass focused and parasite resistant terminal sires.

\section{Texel and Suffolk parasite differences}

The SU and TX breeds are potential terminal sire options for producers in the eastern US, however, parasite resistance of crossbred offspring is critical to their survival in forage-based systems. Comparison of these two sire breeds is limited when observing interaction with GIN, but studies using purebred sheep demonstrate an advantage in GIN resistance of TX sheep. During this experiment, TX had higher eosinophils levels as well as increased levels of serum antibodies compared to SU lambs. Additionally, mucosal antibodies and FEC were negatively correlated in TX, indicating greater humoral response was associated with lower fecal egg output (Sayers et al., 2007). Suffolk sheep showed signs of greater tissue damage with higher leukocyte and pepsinogen levels while infected with GIN (Sayers et al., 2007). Greater FEC, as well as abomasal worm counts were observed in SU compared to TX, in lambs as well as adult ewes (Good et al, 2006). Between the TX and SU breeds, a greater immune response to GIN infection does exists in TX sheep, resulting in a decreased FEC and abomasal worm count when compared to the SU (Good et al., 2006). These data suggest an opportunity for forage-based producers to utilize a terminal sire with improved GIN resistance. 


\section{Terminal sire comparison of critical performance traits}

Growth and carcass merit are primary advantages that terminal sires possess when compared to maternal breeds of sheep. Advantages also exist amongst sire breeds with differences between the SU and TX breeds. These differences result in variation within live sale and carcass pricing between the breeds. Quality measures that impact carcass value consist of live weight, and carcass weight. Further carcass evaluation places value on USDA Yield, quantifying $12^{\text {th }}$ rib backfat (FT), body wall thickness (BWT), and Quality (maturity, flank streaking, conformation). These terminal sire breeds have been labeled as such for their superior carcass characteristics and their ability to improve carcasses of crossbred offspring.

In the past, black-faced breeds (Suffolk, Hampshire, Shropshire) have been the primary terminal sire for producers across the United States. However, in the UK, white-faced Texel (TX) breed has proven to be the premier terminal sire for crossbred offspring (Latif and Owen, 1980). Importation of TX sheep to the US in 1985 has led to a multitude of terminal sire comparison studies at the US Meat Animal Research Center (Leymaster and Jenkins, 1993; Shackelford et al., 2012) as well as the US Sheep Experiment Station (Leeds et al., 2012; Mousel et al., 2012; Notter et al., 2012; Kirschten et al., 2013). These studies have evaluated TX, SU, and composite breeds to compare growth and carcass merit along with lamb survivability. Results have indicated TX sheep have potential as terminal sires in the US to improve performance in crossbred lambs.

One of the greatest concerns of TX sires is dystocia of crossbred progeny. Birth weights (BWT) are a means to measure lambing ease as well as assessing lamb survivability (Leeds et al. 2012). Birth weight, along with other growth traits such as weaning weight (WWT) and postweaning weight (PWWT) have a positive genetic correlation (Notter et al. 2014). Though BWT 
remains inconsistently significant when comparing SU and TX crossbred progeny. Initial studies of terminal sire fitness with TX-sired lambs showed no difference in BWT compared to SU-sired offspring (Leymaster et al. 1993, Ali et al. 2005). However, recent studies have shown TX-sired lambs to have lower BWT than SU-Sired lambs and show limited need for assistance (Leeds et al. 2012). With these recent observations, TX sires have proven that concern for dystocia and lambing assistance is invalid in crossbred mating systems.

In the US, weaning traditionally occurs anywhere from 45-120 days of age, depending on needs of an individual operation. Weaning weights are a measurement of a lambs' genetic potential for growth as well as maternal milk, and intangible maternal characteristics. In the UK, a variety of studies have been conducted comparing WWT of TX to various sires. Lambs weaned at 4 months of age had no difference of WWT across breed (Cameron et al., 1985). Similar results were found in earlier studies of UK terminal breeds when lambs were weaned at an earlier 6 weeks of age (Latif et al., 1979). More recent studies conducted in the US had similar results, finding no difference between TX and SU-sired lambs (Leymaster et al., 1993; Ali et al., 2005). However, in the range-based production experiment, SU- sired lambs had a WWT advantage over TX-sired lambs at weaning of 132 days (Leeds et al., 2012). Some differences may stem from genetic differences over time as well as genetic differences of UK and US terminal sires.

\section{Growth}

Post-weaning management of offspring is highly farm dependent. Nonetheless postweaning performance measures a lambs' ability to grow and reach maturity. These measurements take place between weaning and a weight appropriate for slaughter. Early UK studies have found PWWT growth rate varies between SU and TX-sired lambs, but SU-sired lambs tend to hold an advantage. Latif and Owen (1979 and 1980) found no difference in 
PWWT of TX and SU-sired offspring in both grass-based and concentrate fed studies. However, by 14 weeks of age, weight differences favored SU-sired lambs, as well as a greater PWWT ADG in Ireland (More et al., 1777). Later research also documented a difference of bodyweight at slaughter, favoring SU-sired lambs over TX-sired progeny. Studies conducted in the U.S overwhelmingly indicate superior growth of SU- compared to TX-sired lambs. Lambs sired by SU rams exhibited a greater weight at slaughter (for all slaughter points up until $189 \mathrm{~d}$ of age) (Leymaster et al., 1993). This trend was consistent with western production systems, as SU- sired lambs outgrew and remained heavier than TX-sired lambs (Mouse et al., 2012).when weighed at $216 \mathrm{~d}$ of age, SU sires produced heavier lambs, retaining an ADG advantage over TX offspring (Shackleford et al., 2012; Ali et al., 2005). These studies proved US SU-sired lambs are capable of reaching a greater end weight but met that end weight quicker than TX-sired lambs. This improved growth not only was expressed in increased end weight but also as post-weaning ADG compared to US TX sires. Offspring of SU sires exhibited greater ADG in range-based production trials during the post-weaning period (Notter et al., 2012). Along with ADG, SUsired lambs had greater Gain:Feed (G:F) ratios as well as a higher residual feed intake (RFI). RFI was higher for SU-sired lambs compared to all other breeds for the initial $45 \mathrm{~d}$ on test, whereas TX-sired lambs had the lowest RFI values for the study duration (Kirschten et al., 2013). This high G:F ratio observed in SU-sired lambs may result from differences in mature body size of SU in comparison to other terminal breeds in the study. Suffolk-sired lambs undeniably possess improved genetic merit for growth over TX lambs in US breeding programs. Western production systems credit larger animals with a heavier end weights, providing an economic advantage for SU sires in this region. Larger end weights are required for these traditionally terminal animals, in order to reach a level of carcass acceptability in the marketplace. However, other terminal sire 
options such as TX may prove to have advantageous carcass characteristics, and feed efficiency, allowing for earlier slaughter dates (Kirschten et al., 2013).

\section{Carcass Comparison}

Marketing systems throughout the US vary, placing value either on a carcass or live animal evaluation. The TX has been a valuable asset to both UK and US producers for both carcass quality, and composition. Previous studies have compared SU and TX sires, as well as other terminal sire breeds for their ability to generate improved carcass merit in offspring. Testing in the UK recorded increased dressing percent (DP) of TX-sired lambs in comparison to SU-sired lambs (Wolf et al.,1990), though SU-sired lambs had heavier carcasses at fewer days of age than TX-sired lambs (More et al., 1977). Further research indicated change in diet impacted both hot carcass weight $(\mathrm{HCW})$ as well as DP between the two breeds. Increased levels of energy in the diet allowed for improvement of HCW and DP in TX-sired lambs (Latif et al., 1980). Improvement of HCW and DP held stable for later work, examining carcass composition and eating quality of crossbred progeny (Ellis et al., 1997). Carcass length was shorter for TX-sired lambs but follows live animal composition for frame size (More et al., 1977). More et al., 1997 also found that TX-sired lambs had a larger percentage of lean muscle, as well as greater lean to bone ratio, and loin muscle area (LMA).

Further UK research evaluated at TX-sired lambs on forage-based operations utilizing a variety of forage species. Offspring of both TX and SU sires were analyzed at the same levels of subcutaneous fat. Lambs sired by TX rams had higher quality lean carcasses than SU-sired lambs, as well as greater loin muscle depth (Kempster et al., 1987) and TX-sired lambs had a higher lean-to bone ratio. Overall, UK studies report that TX-sired lambs produced leaner 
carcasses, with a high percentage lean to bone, minimizing excessive trim which ultimately adds value.

Studies also considered sensory evaluation and found no differences in these leaner carcasses (Ellis et al., 1997). Initial work following importation of TX to the US comparing carcasses of various terminal sires. Lambs sired by TX rams had leaner carcasses at lighter carcass weights, with no difference in LMA (Leymaster et al., 1993). Lambs sired by SU rams had greater $\mathrm{HCW}$, as expected with increased liveweight at time of slaughter. No difference was found between the two breeds for, KPH measurements as well as USDA Quality grade (Shackelford et al., 2012; Leymaster et al., 1993). Sensory and palatability data were tested and yielded no difference between the two breeds. Ultimately, SU-sired lambs had greater carcass weights when compared to all other breeds. However, leaner TX-sired carcasses required less trimming than SU-sired lambs. Findings from these studies show TX sires are a suitable option for terminal sire use in the US sheep industry (Leymaster et al., 1993). Primary use should be focused in eastern US markets where lighter carcasses with greater muscling are desired by ethnic consumers. 


\section{Chapter 2: Materials and Methods}

\section{Management}

Crossbred ewes comprised of Dorset and Suffolk genetics were randomly sorted into 4 breeding groups ( $\mathrm{n}=14$ /ram/group) and exposed to TX or SUF rams. TX (n=2) and SUF rams $(n=2)$ were sourced from West Virginia University and Virginia Tech, with selection criteria based on breeding soundness and comparable estimated breeding values for growth and muscling. Breeding groups were managed on similar pasture conditions from late October till the start of December, when rams were removed. Ewes were then managed as one group on forage and dry hay until adequate spring forage was available. Ewes were ultrasounded at an average of 60 days of gestation for pregnancy detection and fetal counts. $92 \%$ of ewes were confirmed pregnant, and 52 ewes began lambing April $4^{\text {th }}$ concluding May $1^{\text {st }}$. Lambing occurred on pasture and pairs were then moved inside to jugs for 24-48 hrs. and upon removal ewes and lambs were placed back onto pasture. A total of 100 lambs were delivered from 52 ewes, for a $192 \%$ lambing rate. Lambs were managed on pasture as one group with their dams, with ad libitum access to $16 \% \mathrm{CP}$ ground creep feed during late lactation. Lambs were weaned June $14^{\text {th }}$ at approximately 60 days of age and were placed into a dry lot. At weaning FEC, PCV, and weights were recorded in order to evaluate parasite load. At the time of weaning all lambs were dewormed with Levamisole (Agrilabs, St. Joseph, MO), at the rate of $8 \mathrm{mg} / \mathrm{kg}$. Lambs remained in a dry lot for two weeks for monitoring and feed acclimation before starting the grazing trial. Lambs weighing less than $14 \mathrm{~kg}$, or those that were artificially reared were excluded from the experiment. Remaining lambs $(n=82)$ were separated into 2 large groups by breed, then subdivided into 3 smaller groups, for a total of 6 treatment groups. 


\section{Grazing Design}

Remaining lambs $(n=82)$ were initially separated by sire and then randomly assigned to one of three replicates per sire, for a total of 6 groups. TX-sired lambs were separated into three replicates T1, T2, T3 ( $\mathrm{n}=14, \mathrm{n}=13, \mathrm{n}=13$ respectively), and SUF-sired lambs into $\mathrm{S} 1, \mathrm{~S} 2, \mathrm{~S} 3$ ( $\mathrm{n}$ $=14, \mathrm{n}=14, \mathrm{n}=14)$. Treatment groups were rotated through 9 pasture movements starting July $2^{\text {nd }}$, and continued through October $2^{\text {nd }}$ concluding the project. Lambs rotated through paddocks in a diagonal pattern each movement, to ensure that replicates experienced the entire pasture.

\begin{tabular}{|c|c|c|c|}
\hline Movement 1 & Movement 2 & Movement 3 & Movement 4 \\
\hline S1 & $\mathrm{T} 1$ & $\mathrm{~S} 2$ & $\mathrm{~T} 2$ \\
\hline $\mathrm{T} 1$ & $\mathrm{~S} 2$ & $\mathrm{~T} 2$ & $\mathrm{~S} 3$ \\
\hline $\mathrm{S} 2$ & $\mathrm{~T} 2$ & $\mathrm{~S} 3$ & $\mathrm{~T} 3$ \\
\hline $\mathrm{T} 2$ & $\mathrm{~S} 3$ & $\mathrm{~T} 3$ & $\mathrm{~S} 1$ \\
\hline $\mathrm{S} 3$ & $\mathrm{~T} 3$ & $\mathrm{~S} 1$ & $\mathrm{~T} 1$ \\
\hline $\mathrm{T} 3$ & $\mathrm{~S} 1$ & $\mathrm{~T} 1$ & $\mathrm{~S} 2$ \\
\hline
\end{tabular}

Movements were planned for every 14 days but was ultimately determined by average forage height within paddocks. Average movement intervals occurred every 10.3 days, across the 93-d grazing trial. Lambs began the experiment in 0.036 ha paddocks and gradually increased in size to a final area of 0.11 ha to accommodate increase in weight. After grazing, paddocks were clipped to a uniform height, allowing for high quality regrowth. Area containing paddocks, 1,2 and 3 were re-grazed in paddocks 7,8 , and 9 . These later paddocks were rotated $90^{\circ}$ to ensure random forage quality and parasitic reinfection across all treatment groups. 


\section{Lamb Management}

Lambs were placed into grazing paddocks July $2^{\text {nd }}$ and had ad libitum access to forage and water at the WVU Organic Farm. Supplementation was provided at $2 \%$ of BW and was adjusted every two weeks to current BW. Samples for determination of FEC, PCV, BW, and FAMACHA scores were recorded bi-weekly, until August. FAMACHA ${ }^{\mathrm{TM}}$ scores were taken weekly and lambs with a FAMACHA score of 3 or higher were treated with Levamisole (Agrilabs, St. Joseph, MO) orally at the rate of $8 \mathrm{mg} / \mathrm{kg}$. Ultrasonic REA and fat depth measurements (Ibex Pro, E.I. Medical Imaging, Loveland, CO) were taken on all lambs before being sold at a graded auction at the close of the grazing trial.

\section{Pasture Measurements}

Forage areas used in this study were previously utilized for hay production as well as grazing of the ewe flock. Grass species were primarily composed of tall fescue (Schedonorus arundinaceus), and Orchardgrass (Dactylis glomerate). Legumes in the paddock were primarily red and white clovers (Trifolium pretense, Trifolium repens). Additional red clover was frost seeded during winter months before this study at a rate of $2.24 \mathrm{~kg} / \mathrm{ha}$ to improve pasture quality. Forage heights were taken using a rising-plate meter both pre- and post-grazing, at least 20 heights were taken at regularly spaced intervals throughout every paddock. Botanical composition of forage provided was established using 2 samples clipped at height measurements 10, and 18 in every paddock. Botanical samples were taken both pre- and post-grazing. These samples were dried in a forage oven at $55^{\circ} \mathrm{C}$ and weights were taken on grass, legumes, forbes, dead material.

\section{Parasitological Analysis}

Fecal egg count was performed using a modified McMaster's technique (Whitlock, 1948). Fecal samples were collected from animals and $2 \mathrm{~g}$ of feces was mixed with $28 \mathrm{ml}$ of saturated salt solution (Specific gravity 1.20) and contents were filtered through double layered 
cheesecloth to extract large particles. Strongylid-type eggs were enumerated under 100X magnification in McMaster counting slides (Chalex, Olympia, Oregon) and multiplied by 50 to determine eggs/g of feces. Additional feces were kept and cultured in order for larval speciation. Feces were mixed with peat moss, activated charcoal, and stored at $22^{\circ} \mathrm{C}$ for 14 days to allow L3 development. Larvae was collected using a Baerrman technique, filtering larvae from culture sediment. Larvae were fixed using a formalin solution for speciation. Species was determined by comparing general larval length and tail sheath length (Wyk and Mayhew, 2013).

\section{Auction Grading}

All lambs were sold through the Mt. Vernon, $\mathrm{OH}$ branch of United Producers. Lambs were evaluated by a trained livestock grader and were assigned groups based on phenotypic compositional differences. Grading scale classification consisted of 5 categories, Grade, Low choice, Choice, High choice, and Prime. Groups of lambs were then weighed and penned separately until sold. Lambs were sold based on grouping, price breakdowns and grading data were provided at the sale conclusion. 


\section{Chapter 3: Statistical Analysis}

Statistical analysis was conducted using SAS (SAS Institute Inc., Cary, NC). Data were analyzed using the MIXED model procedure of SAS, using the fixed effects of sire breeds. Repeated measures were used for weight as well as infection data (FEC, PCV and FAMACHA). The repeated measures used fixed effects of the sire breed as well as sire breed and time. The FEC were log transformed for normality. Sire breed and sex of lambs at each sampling and total ADG values were analyzed with Proc GLM. Statistical analysis for evaluation of deworming frequency differences used the GENMOD procedure. Pricing data were determined by pen difference and separation by grading at auction facilities and values determined by actual $\$ / \mathrm{cwt}$. assigned. Statistical significance was accepted at $\mathrm{P}<0.05$ for all measures. 


\section{Chapter 4: Results}

\section{Animal Growth}

No sire breed effect was observed on birth weight, survivability, or incidence of dystocia.

Lambs were managed as one group until weaning yet minor differences were observed at weaning as SU-sired lambs weighing $0.44 \mathrm{~kg}$ greater $(P=0.45)$ than TX-sired lambs (Table 1$)$. Average WWT for SU- and TX-sired lambs were $22.07 \mathrm{~kg}$ and $21.63 \mathrm{~kg}$ respectively. Postweaning and for the study duration ADG differences did not differ between sire $(0.13 \mathrm{~kg} / \mathrm{d} \mathrm{SU}$, $0.14 \mathrm{~kg} / \mathrm{d}$ TX respectively; $P=0.42$ ). Additionally, total weight gain was not significantly different between SU- and TX-sired lambs (12 kg, $14 \mathrm{~kg}$ respectively; $P=0.42)$ (Fig. 1). Final weights also were not different between SU- and TX-sired lambs $(34.55 \mathrm{~kg}, 35.33 \mathrm{~kg} ; P=0.34)$ (Table 1).

\section{Compositional Differences}

Live carcass data were collected by ultrasound 1-d before lambs were sold, to determine sire breed effects on carcass compositional differences. Lambs sired by TX rams had significantly greater REA than SU-sired lambs $\left(11.56 \mathrm{~cm}^{2}, 9.42 \mathrm{~cm}^{2}\right.$, respectively; $\left.P<0.0001\right)$ (Table 1). TX-sired lambs also were found to possess leaner carcasses with lower FD values than SU-sired lambs $(.16 \mathrm{~cm}, .19 \mathrm{~cm}$, respectively; $P<0.0001)$ Weight of the lambs at the time of ultrasound was not statistically different.

\section{Auction Grading and Pricing}

Lambs were separated by breed and graded for conformational differences to apply pricing breakdowns. Grading scale classification consisted of 5 categories, Grade, Low choice, Choice, High choice, and Prime (Table 2). Grading revealed that $76.9 \%$ of TX-sired lambs graded low choice or higher, whereas $100 \%$ of SU-sired lambs graded at grade $(P<0.0001)$ (Figure 4). Lambs from TX-sired groups qualified for prime classifications, and due to level of composition sold for a premium. Lambs sired by TX rams had higher pricing data than SU-sired 
lambs. TX-sired lambs brought an average price of $\$ 119.43 / \mathrm{hd}$ whereas SU-sired lambs $\$ 99.63 /$ hd. On average TX-sired lambs returned $\$ 19.80 /$ hd more than SU-sired lambs $(P<0.05)$. Since weight was equivalent between sire groups then composition of lambs sold was driving premiums received.

\section{Parasitological Results}

While grazing pastures lambs became naturally infected. As a result, both sire groups experienced PCV reduction. Lambs requiring anthelmintic treatment were excluded from the data after treatment but remained in the paddocks until project conclusion. At the beginning of the study, average PCV was measured at $30.77 \%$ and concluded at $23.18 \%$. By study completion, TX-sired lambs had higher PCV compared to SU-sired lambs (27.5\%, 26.9\% respectively; $P=0.01$ ) [Figure 2C]. Despite having higher PCV scores at study end, TX- sired lambs did have a higher parasite load than SU-sired lambs (778 eggs/g, 477 eggs/g respectively, $P=0.05)[$ Figure 2A]. FAMACHA@ scores showed significantly lower FAMACHA scores for TX- sired lambs following week one $(P<0.05)$. Based on FAMACHA scores deworming treatment was administered orally and deworming frequency was found to be greater in SU-sired lambs than TX-sired lambs. Throughout the study, 39\% of SU-sired lambs required deworming, whereas only $13 \%$ of TX-sired lambs were dewormed $(P<0.0001)$ [Figure 2B]. Deworming frequency in SU-sired lambs explains, at least in part, differences in FEC between sire groups.

\section{Pasture Analysis}

Herbage mass offered to all groups was similar with no statistical difference for all grazing periods $(\mathrm{P}=0.22)$. Herbage mass changed slightly over time between movements but remained consistent for treatment groups. Herbage mass was calculated from residuals after grazing time points. Residual herbage mass was equivalent for each group $(P=0.66)$, indicating similar forage disappearance between sire groups. Additionally, residual herbage mass didn't 
change over time between grazing movements $(\mathrm{P}=0.82)$, perhaps due to moving lambs based on average forage height as opposed to set time points. Botanical composition was analyzed to determine similarity of plant families being offered to each grazing paddock. Before and after grazing samples were separated into four categories, grass, legumes, forbs, dead. From these categories no significant difference was found in forage offered, or disappearance between grazing treatments $(P=0.66)$. Therefore, an equivalent and comparable offering of forage was provided at each movement throughout grazing periods. Furthermore, forage analyses revealed consistent quantity of grazing material being offered throughout all movements of the study (data not shown).

\section{Chapter 5: Discussion}

Texel sired lambs brought $\$ 19.80 /$ hd more than SU-sired lambs when sold at a graded auction. Eastern sheep operations differ on when and how lambs are marketed, therefore sire selection may play a vital role in economic advantage for producers. Terminal sire comparison tested at the US Sheep Experiment Station provided reference for expected outcomes in mating systems using Texel and Suffolk sires on western range operations. In this evaluation lambing ease showed no difference between SU and TX sires (16.8\% vs $15.5 \%$, respectively), though birthweights were significantly higher in SU-sired lambs $(5.5 \mathrm{~kg}$ vs $5.26 \mathrm{~kg}, P<0.01)$ (Leeds et al., 2012). Comparatively, lambs produced in the current project did not have any record of dystocia, as well as birthweight difference for TX- or SU-sired lambs (4.28 kg, $4.36 \mathrm{~kg})$. Lack of dystocia and decreased lambing difficulty may be due to a decreased birthweight and ewe breed. Lambs from Dubois, ID, had similar WW between sire breeds, though weaning occurred at 132d as opposed to $60 \mathrm{~d}$ in the current trial. Extended weaning intervals showed no improvement for 
either sire breed in Dubois. However, advantage of SU-sired lambs was demonstrated in postweaning growth as expected. Average daily gain for SU lambs was significantly higher for the feeding duration across all years compared to TX-sired offspring ( $0.3 \mathrm{~kg} / \mathrm{d}$ vs. $0.24 \mathrm{~kg} / \mathrm{d})$ (Leeds, et al., 2012). This may not be comparable to grass-based performance, due to feeding high concentrate diets to lambs in the study (Notter et al., 2012). With the model used in Dubois, ID, high growth SU offspring performed as expected when placed into a high-input system lacking parasite pressure.

To evaluate terminal sires for eastern US production, low input strategies as well as concern for parasite impact must be considered. Grass-based production modeled in the current study reported no difference between TX-sired vs. SU-sired lambs for post-weaning growth (ADG: 0.13 vs. $0.14 \mathrm{~kg} / \mathrm{d}$ ). Suffolk sires selected for the current study were moderate in growth EBV's and heavier muscled, than traditional SU rams used in range operations. The TX sire offers an alternative to the traditional SU terminal sire and like the selection of the SU sires, offer a moderate frame better suited to grass based production.

Traditionally TX-sires have been used to improve muscling and overall carcass characteristics in crossbred progeny (Wolf et al., 1980). Lambs sired by TX rams were comparable to SU-sired lambs for growth but proved advantageous with ultrasound measurements. Lambs sired by TX rams had significantly greater LEA than SU-sired lambs $\left(11.7 \mathrm{~cm}^{2}, 9.4 \mathrm{~cm}^{2}\right.$, respectively; $\left.P<0.0001\right)$. These values correlate with live market grading as Texel-sired lambs had leaner carcasses with lower fat depth values than SU-sired lambs $(0.17$ $\mathrm{cm}, 0.19 \mathrm{~cm}$, respectively; $P<0.0001)$. Although not possible to measure and report leg score data in live evaluation studies, a large portion of the visual grading is leg mass. This portion of the carcass is drastically improved in purebred TX lambs, with improvement occurring in 
crossbred progeny (Mousel et al., 2012). Overall, auction grading of lambs favored TX-sired lambs, providing additional advantages over SU-sired lambs for pricing and phenotypic evaluation. Lambs were sold averaging similar weights at time of sale, with a difference of 0.92 $\mathrm{kg}(P=0.34)$. Lambs were broken into five grading levels, grade, low choice, choice, high choice, and prime. When grades are separated by sire breed, 100\% of SU-sired lambs were sold at grade and $23.1 \%$ of TX-sired lambs classified as grade, making up groups with the lowest \$/cwt. Lambs sold at low choice, choice, high choice, and prime were all TX-sired lambs. Average pricing for lambs favored TX-sired lambs with a difference of $\$ 19.80 /$ hd. Previous research does not compare economic advantage of terminal sires, where graded auctions are available. Current pricing data shows TX-sires could be beneficial to producers who can capitalize on non-traditional markets.

Increasing research with grass-based lamb feeding places parasite control as a top priority. Lambs with some level of parasite resistance prove valuable in these systems, decreasing both labor and mortality. Weaning FEC was similar between SU- and TX-sires, 179 eggs/g and 161 eggs/g, respectively. After exposure to pasture, FEC remained stable until late August. Increase of parasitic infection allows for greater chance of reinfection, creating a surge in FEC values. Accompanying the rise of FEC was an expected decline in PCV scores, and consequently a greater number of lambs requiring deworming in September. At study initiation, PCV scores showed little separation, averaging 30.78\% across all lambs. Between weeks 10 and 11, FEC was significantly higher in TX-sired lambs and can be explained by exclusion of lambs receing deworming treatment, which were primarily SU-sired. During the study, $87 \%$ of TXsired lambs did not receive a deworming treatment, compared to $62 \%$ of SU-sired lambs. Removal of treated animal values did not change PCV values of SU-sired lambs and continued 
to fall. Suffolk-sired lambs' PCV were lower than TX-sired lambs by trial completion. Final PCV measurements for SU- and TX-sired lambs were $22.7 \%$ and $23.7 \%$ respectfully. TX-sired lambs were able to withstand larger parasite loads and remain untreated, resulting in decreased labor input, showing greater parasite tolerance. These findings are congruent with data reported from research in Ireland reporting significantly lower FEC in TX-sired lambs compared to SU offspring (Good et al., 2006). Data from this study provides additional evidence for parasitological advantage of TX sires in grass-based systems.

Performance of lambs in this experiment exemplify the level in which environmental factors affect lambs growth throughout summer months. Pricing data reveal an opportunity to capitalize on graded auctions found in the eastern US. Moreover, these data support the use of TX rams in efforts to improve enterprise profitability. Pricing data paired with TX-sired offspring's ability to withstand high parasite infections without anthelmintic treatments, justify the need for their utilization. Texel sires provide a unique opportunity for producers to increase profitability in grass-based systems when compared to traditional SU terminal sires in the eastern US 
Table 1: Production parameters of Texel- and Suffolk-sired offspring

\begin{tabular}{lcccc}
\cline { 2 - 3 } Item & Sexel & Suffolk & Pooled SE & P-Value \\
\hline Number & 39 & 42 & - & - \\
Birthweight (kg) & 4.28 & 4.36 & 0.117 & - \\
Weaning Weight (kg) & 21.63 & 22.07 & 0.41 & 0.45 \\
Average Daily Gain (kg/d) & 0.13 & 0.14 & 0.025 & 0.42 \\
Sale Weight (kg) & 35.33 & 34.55 & 0.595 & 0.34 \\
Fecal Egg Count (eggs/g) & 748.6 & 449.1 & 149.9 & 0.046 \\
Packed Cell Volume (PCV) (\%) & 27.52 & 26.90 & 0.19 & 0.095 \\
Ribeye Area $\left(\mathrm{cm}^{2}\right)$ & 11.56 & 9.42 & 0.34 & 0.0001 \\
Fat Depth & 0.16 & 0.19 & 0.09 & 0.07 \\
\hline
\end{tabular}

\footnotetext{
${ }^{1}$ Number of lambs sired by Suffolk, and Texel rams

${ }^{2}$ ADG calculated during grazing trial

${ }^{3}$ FEC and PCV averaged across grazing trial

${ }^{4}$ Ultrasound data collected before live auction evaluation
} 
Table 2: Auction grading of Texel- and Suffolk-sired offspring

\begin{tabular}{lcc}
\hline \multicolumn{1}{c}{ Grade } & AVG Wt. Range (lbs) & \$/cwt \\
\hline Grade & $47-100$ & $\$ 100-150$ \\
Low Choice & 74 & $\$ 160$ \\
Choice & 75 & $\$ 170-175$ \\
High Choice & 69 & $\$ 185$ \\
Prime & 53 & $\$ 200$ \\
\hline
\end{tabular}


Table 3: Auction earnings based on sire breed

\begin{tabular}{lcccc}
\hline Sire Breed & No. Total & AVG Wt. (kg) & AVG \$/cwt & \$/hd \\
\hline Suffolk & 41 & 42.44 & 167.14 & $\$ 99.63$ \\
Texel & 39 & 42.90 & 128.00 & $\$ 119.43$ \\
\hline
\end{tabular}




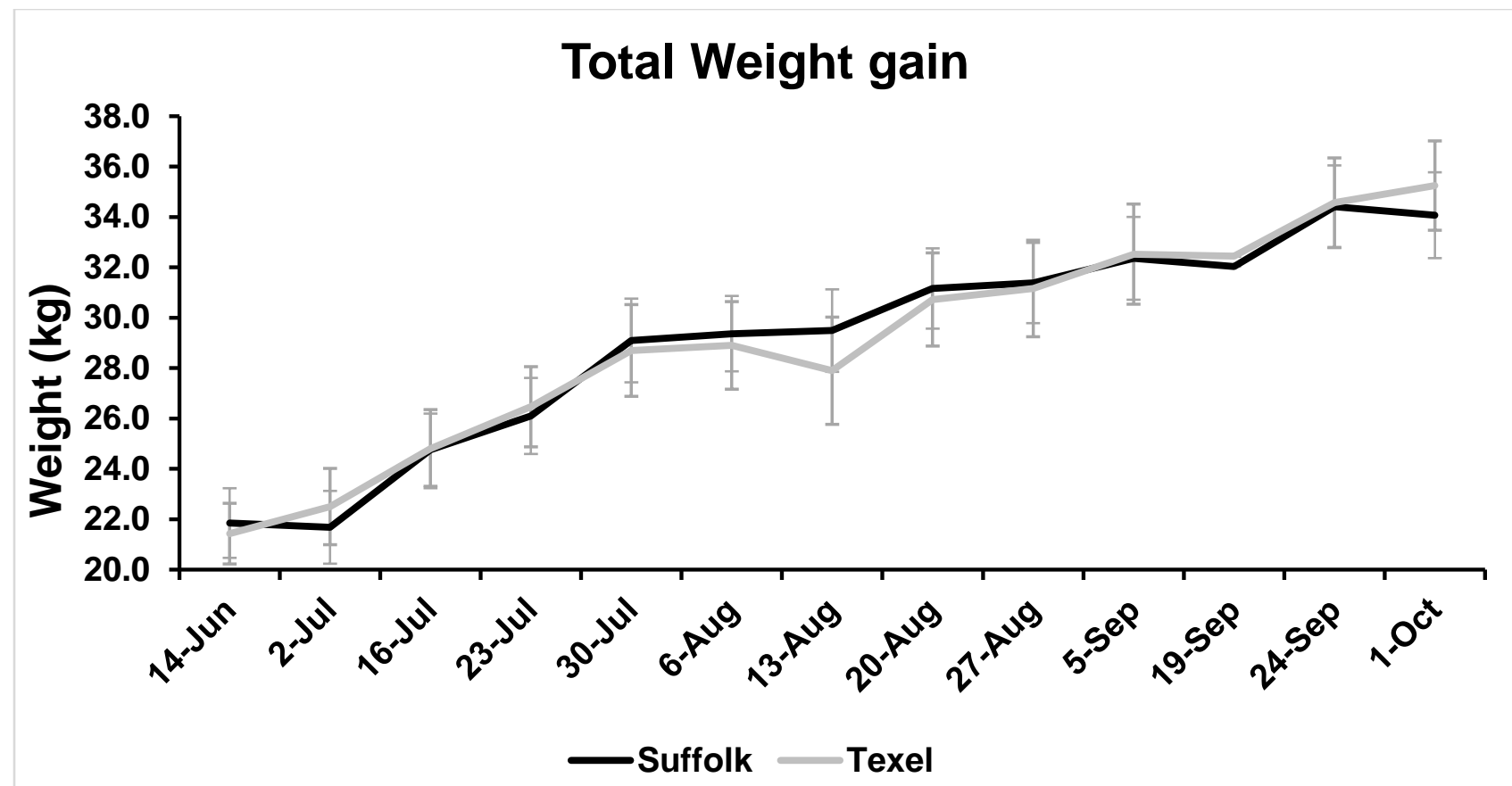

Figure 1: Growth measures of Texel and Suffolk-sired offspring

Total weight gain, starting with $60 \mathrm{~d}$ weaning weights and continuing for 111 days. 


\section{Auction Grading}

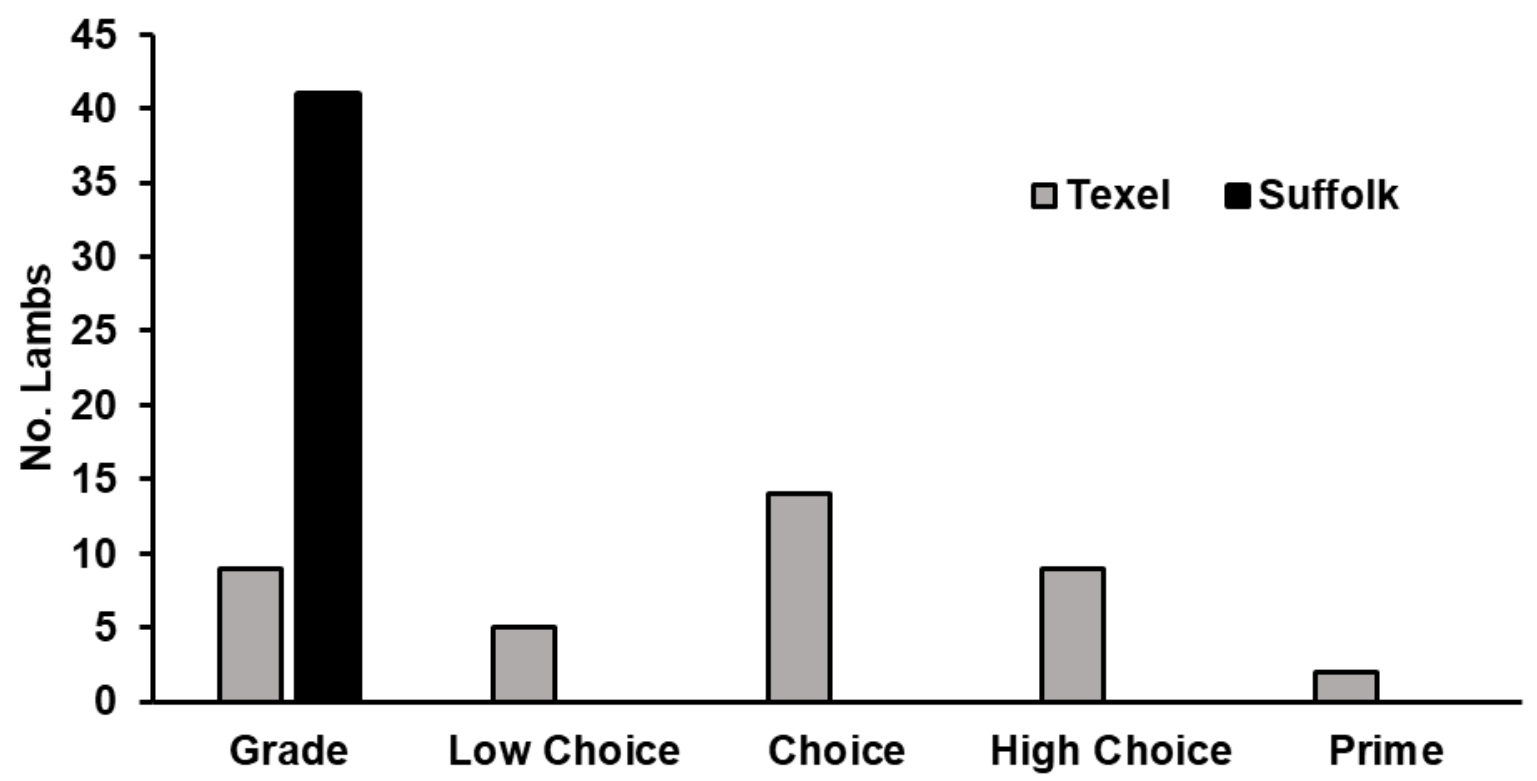

Figure 2: Auction grading breakdown of Texel- and Suffolk-sired offspring

Number of lambs included in each grading breakdown, represented by sire. 
(A)

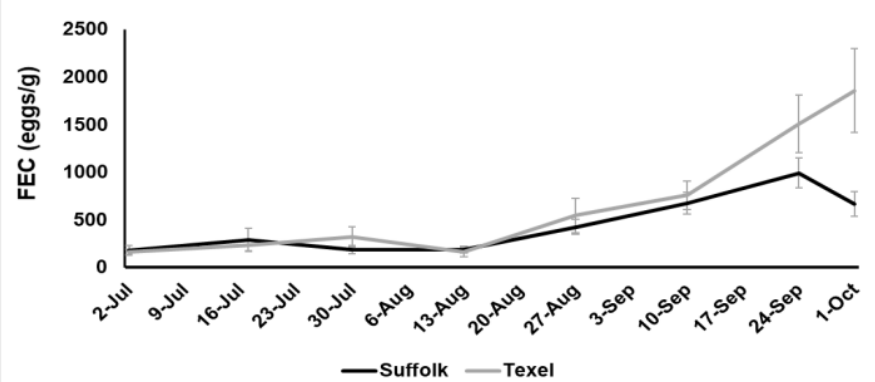

(B)

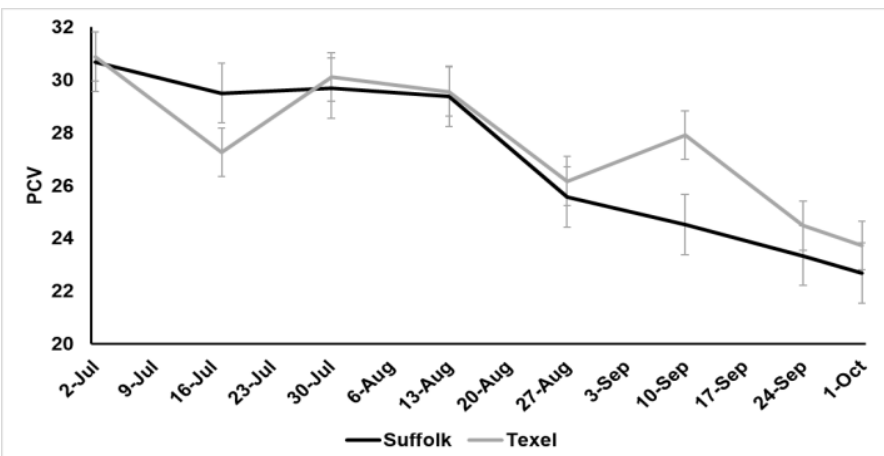

(C)

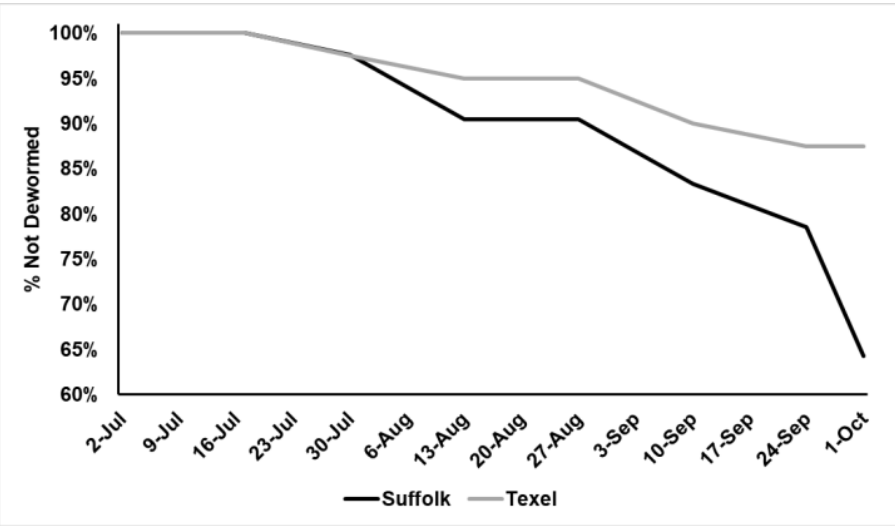

Figure 3: Parasite infection of Texel and Suffolk-sired offspring

FEC (A) and PCV (B) from the start of the grazing trial, and continuing through the course of the study. Lambs that did not require an anthelmintic treatment $(\mathrm{C})$, shown as a percent of the respective sire group population. 


\section{Literature Cited}

Ali, A., D.G. Morrical, and M.P. Hoffman. 2005a. Evaluating Texel-, Suffolk-, and Columbia sired offspring: I. Prolificacy, survival, and preweaning growth traits under a forage based lambing system. Prof. Anim. Sci. 21: 427-433. doi: 10.15232/S10807446(15)31246-8.

Bengtsson J., J. M. Bullock, B. Egoh, C. Everson, T. Everson, T. O'Connor, P. J. O'Farrell, H. G. Smith, R. Lindborg. 2019. Grasslands-more important for ecosystem services than you might think. Ecosphere. 10 (2): e02582. 10.1002/ecs2.2582

Burke, J., Apple, J., Roberts, W., Boger, C., \& Kegley, E. (2003). Effect of breed-type on performance and carcass traits of intensively managed hair sheep. Meat Science, 63(3), 309-315. doi: 10.1016/s0309-1740(02)00087-6

Burke, J. M., J. E. Miller, D.D. Olcott, B.M. Olcott, T.H. Terrill. 2004. Effect of copper oxide wire particle dosage and feed supplement level and Haemonchus contortus infection in lambs. Vet Parisitol. 123(3-4):235-243

Burke, J. M., J. E. Miller, T.H. Terrill. 2009. Impact of rotational grazing on management of gastrointestinal nematodes in weaned lambs. Vet. Parasitol. 163(1-2): 67-72

Cameron, N.D., and D.J. Drury. 1985. Comparison of terminal sire breeds for growth and carcass traits in crossbred lambs. Anim. Prod. 40:315-322.

Colvin, A. F., S. W. Walkden-Brown, et al. (2008). Intensive rotational grazing assists in the control of gastrointestinal nematodosis of sheep in cool temperative environment with summer dominant rainfall. Vet. Parasitol. 153(1-2): 108-120

Ellis, M., G.M. Webster, B.G. Merrell, and I. Brown. 1997. The influence of terminal sire breed on carcass composition and eating quality of crossbred lambs. Anim. Sci. 64:77-86. doi: $10.1017 /$ S1357729800015575.

Gamble, H.R., Zajac, A.M. 1992. Resistance of St. Croix lambs to haemonchus contortus in experimentally and naturally acquired infections. Vet. Parisitol., 41, 211-277

Good, B., J.P Hanrahan, B.A Crowley, and G. Malcahy. 2005. Texel sheep are more resistant to natural nematode challenge than Suffolk sheep based on faecal egg count and nematode burden. Vet. Parasitol. 136: 317-327. doi: 10.1016/j.vetpar.2005.12.001.

Healey, K., Lawlor, C., Knox, M. R., Chambers, M., Lamb, J., \& Groves, P. (2018). Field evaluation of Duddingtonia flagrans IAH 1297 for the reduction of worm burden in grazing animals: Pasture larval studies in horses, cattle and goats. Veterinary Parasitology, 258, 124-132. doi: 10.1016/j.vetpar.2018.06.017

Jacques, J., Berthiaume, R., \& Cinq-Mars, D. (2011). Growth performance and carcass characteristics of Dorset lambs fed different concentrates: Forage ratios or fresh grass. Small Ruminant Research, 95(2-3), 113-119. doi:

10.1016/j.smallrumres.2010.10.002 
Kaplan, R.M., and A.N. Vidyashankar. 2012. An inconvenient truth: global warming and anthelmintic resistance. Vet. Parasitol. 186: 70-78. doi: 10.1016/j.vetpar.2011.11.048.

Kaplan, R.M. 2004. Drug resistance in nematodes of veterinary importance: a status report. Trends Parasitol. 20:477-481. doi: 10.1016/j.pt.2004.08.001.

Kempster, A.J., D. Croston, D.R. Guy, and D.W. Jones. 1987. Growth and carcass characteristics of crossbred lambs by ten sire breeds, compared at the same estimated carcass subcutaneous fat proportion. Anim. Prod. 44: 83-98.

Kirschten, D.P., D.R. Notter, T.D. Leeds, M.R. Mousel, J.B. Taylor, and G.S. Lewis. 2013. Evaluation of Columbia, USMARC-Composite, Suffolk, and Texel rams as terminal sires in an extensive rangeland production system: V. Postweaning growth, feed intake and feed efficiency. J. Anim. Sci. 91:2021-2033. doi: 10.2527/jas.2012-5152.

Latif, M.G.A., and E. Owen. 1979. Comparison of Texel- and Suffolk-sired lambs out of Finnish Landrace X Dorset Horn ewes under grazing conditions. J. Agric. Sci. 93:235-239.

Latif, M.G.A., and E. Owen. 1980. A note on the growth performance and carcass composition of Texel- and Suffolk-sired lambs in an intensive feeding system. Anim. Prod. 30:311314.

Leeds, T.D., D.R. Notter, K.A. Leymaster, M.R. Mousel, and G.S. Lewis. 2012. Evaluation of Columbia, USMARC-Composite, Suffolk, and Texel rams as terminal sires in an extensive rangeland production system: I. Ewe productivity and crossbred lamb survival and preweaning growth. J. Anim. Sci. 90:2931-2940. doi: 10.2527/jas.2011-4640.

Leymaster, K.A., and T.G. Jenkins. 1993. Comparison of Texel- and Suffolk-sired crossbred lambs for survival, growth and compositional traits. J. Anim. Sci. 71:859-869.

Mavrot, F., H. Hertzberg, and P. Torgerson. 2015. Effect of gastrointestinal nematode infection on sheep performance: a systematic review and meta-analysis. Parasit. Vectors. 8:557. doi: 10.1186/s13071-015-1164-Z.

McNeilly, T.N., E. Devancy, et al. (2009). Teladorsagia circumcincta in the sheep abomasum: defining the role of dendritic cells in T cell regulation and protective immunity. Para. Immunol. 31(7): 347-356

More O'Ferrall, G.J., and V.M. Timmon. 1977a. A comparison of eight sire breeds for lamb production: 1. Lamb growth and carcass measurements. Irish J. Ag. Res. 16:267-275.

More O'Ferrall, G.J., and V.M. Timmon. 1977b. A comparison of eight sire breeds for lamb production: 2. Lamb carcass composition. Irish J. Ag. Res. 16:277-284.

Mortensen, L.L., L.H. Williamson, T.H. Terrill, R.A. Kircher, M. Larsen, R.M. Kaplan. 2003. Evaluation of prevalence and clinical implications of anthelmintic resistance in gastrointestinal nematodes in goats. J. AVMA. 223:495-500. 
Mousel, M.R., D.R. Notter, T.D. Leeds, H.N. Zerby, S.J. Moeller, and G.S. Lewis. 2012. Evaluation of Columbia, USMARC-Composite, Suffolk, and Texel rams as terminal sires in an extensive rangeland production system. III. Prefabrication carcass traits and organ weights. J. Anim. Sci. 90:2953-2962. doi: 10.2527/jas.2011-4767.

Notter, D.R., M.R. Mousel, H.N. Zerby, L.M.M. Surber, T.D. Leeds, S.J. Moeller, G.S. Lewis, and J.B. Taylor. 2014. Impact of changes in weight, fat depth, and loin muscle depth on carcass yield and value and implications for selectin and pricing of rams from terminal sire sheep breeds. Sheep and Goat Res. J. 29: 36-44.

Notter, D.R., T.D. Leeds, M.R. Mousel, J.B. Taylor, D.P. Kirschten, and G.S. Lewis. 2012. Evaluation of Columbia, USMARC-Composite, Suffolk, and Texel rams as terminal sires in an extensive rangeland production system: II. Postweaning growth and ultrasounic measures of composition for lambs fed a high-energy feedlot diet. J. Anim. Sci. 90:29412952. doi: 10.2527/jas.2011-4641.

Sackett, D., P.H. Holmes., K. Abbott, S. Jephcott, and M. Barber. 2006. Assessing the economic cost of endemic disease on the profitability of Australian beef cattle and sheep producers. Meat and Livestock Australia, North Sydney, NSW. AHW.087.

Sayers, G., B. Good, J.P. Hanrahan, J. O’Donovan, G. Malcahy, and T. Sweeney. 2007. Breed differences in mucosal and systemic antibody response to nematode infection in sheep: an important role for IgE? Parasitology. 135: 71-80. doi: 10.1017/S0031182007003630.

Shackelford, S.D., K.A. Leymaster, T.L. Wheeler, and M. Koohmaraie. 2012. Effects of breed of sire on carcass composition and sensory traits of lamb. J. Anim. Sci. 90:4131-4139. doi: 10.2527/jas.2012-5219.

Shiflett, J.S., G.W. Williams, and P. Rogers. 2010. The nontraditional lamb market: characteristics and marketing strategies. AFCERC Commodity Market Research Report No. CM-02-10.

Soli, F., T. H. Terrill, et al. (2010). Efficacy of copper oxide wire particlesagainst gastrointestinal nematodes in sheep and goats. Vet. Parasitol. 168(1-2):166-171

Terrill, T.H., J.E. Miller, J.M. Burke, J.A. Mosjidis, and R.M. Kaplan. 2012. Experiences with integrated concepts for the control of Haemonchus contortus in sheep and goat in the United States. Vet Parasitol. 186:28-37. doi: 10.1016/j.vetpar.2011.11.043.

USDA-Animal and Plant Health Inspection Service-Veterinary Services-National Animal Health Monitoring System (USDA-APHIS-VS-NAHMS). 1996. Reference of 1996 US sheep health and management practices. United States Department of Agriculture Animal and Plant Health Inspection Service National Animal Health Monitoring System, Fort Collins, CO.

USDA-Animal and Plant Health Inspection Service-Veterinary Services-National Animal Health Monitoring System (USDA-APHIS-VS-NAHMS). 2012. Sheep 2011. Part II. Reference of marketing and death loss on US sheep operations. United States Department of 38 
Agriculture Animal and Plant Health Inspection Service National Animal Health Monitoring System, Fort Collins, CO.

Whittier, D.W., A.M. Zajac, and S.H. Umberger. 2009. Control of internal parasites in sheep. Virginia Cooperative Extension. Publication 410-027.

Wildeus, S. (1997). Hair sheep genetic resources and their contribution to diversified small ruminant production in the United States. Journal of Animal Science, 75(3), 630. doi: $10.2527 / 1997.753630 x$

Wolf, B.T., C. Smith, and D.I. Sales. 1980. Growth and carcass composition in the crossbred progeny of six terminal sire breed of sheep. Anim. Prod. 31:307-313

Wyk, J. A. V., \& Mayhew, E. (2013). Morphological identification of parasitic nematode infective larvae of small ruminants and cattle: A practical lab guide. Onderstepoort $J$ Vet Res, 80(1). doi: 10.4102/ojvr.v80i1.539

Zajac, A.M. 2006. Gastrointestinal nematodes of small ruminants: life cycle, anthelmintics, and diagnosis. Vet. Clin. North Am. Food Anim. Pract. 22: 529-54. doi. 10.1016/j.cvfa.2006.07.006. 